\title{
KESESUAIAN DAN DAYA DUKUNG EKOWISATA MANGROVE DI DESA KURAU DAN DESA KURAU BARAT KABUPATEN BANGKA TENGAH
}

\author{
Suitability and Carrying Capacity of Mangrove Ecotourism in Kurau Village and West Kurau Village of Central Bangka \\ Regency
}

Meli Zulia ${ }^{1}$ Okto Supratman ${ }^{1}$ Suci Puspita sari ${ }^{1}$

Program Studi Manajemen Sumberdaya Perairan Universitas Bangka Belitung

Email korespondensi : melizulia11@gmail.com

\begin{abstract}
Mangrove ecosystems are one ecosystem that is vulnerable damaged. Mangrove ecotourism is one of the efforts that can do to reduce damage in the utilization of mangrove ecosystems. This study aims to calculate the suitability and carrying capacity of mangrove ecotourism in the Kurau Village and West Kurau Village, Central Bangka Regency. This research was conducted in March 2019 at the Mangrove ecotourism area of Kurau Village and West Kurau Village. The study location determined using a purposive sampling method consisting of 3 substations in one location to get primary data and secondary data. Descriptive method was used to analyze the Tourism Suitability Index (IKW) and the Regional Carrying Capacity (DDK). The calculation results show that the mangrove ecotourism area of Kurau Village is included in the suitable category (S2) with a Suitability Index value is $74.36 \%$ and the Regional Carrying Capacity (DDK) is 44 people per day (10 hours / day) and West Kurau Village is included in suitable category (S2) with a Suitability Index value of 74.36\% and the Regional Carrying Capacity (DDK) is 55 people per day (10 hours open / day).
\end{abstract}

Keywords: Mangrove Ecotourism, Tourism Suitability Index, Regional Capability, Kurau Village and West Kurau Village. PENDAHULUAN

Hutan mangrove merupakan salah satu tipe hutan hujan tropis yang hidup didaerah pesisir yakni tumbuh disepanjang garis pantai perairan tropis dan subtropis yang masih terkena pasang surut air laut (Wibisono, 2004). Mangrove dunia pada saat ini mengalami tekanan, dilihat dari data luas mangrove dunia pada tahun 1980 sampai tahun 2000. Tahun 1980 luas hutan mangrove mencapai 19,8 juta Ha, pada tahun 1990 turun menjadi 16,4 juta $\mathrm{Ha}$, dan pada tahun 2000 luas hutan mangrove mencapai 14,6 juta Ha. Luas hutan mangrove di Indonesia mencapai 4,25 juta Ha pada tahun 1980, pada tahun 1990 turun menjadi 3,53 juta Ha, dan pada tahun 2000 luas hutan mangrove tersisa 2,93 juta Ha (Hernandi et al. 2013). Apabila tidak diimbangi dengan kebijakan pengelolaan yang tepat, kerusakan hutan mangrove akan terus terjadi seiring berjalannya waktu yaitu dengan meningkatnya kebutuhan ruang untuk pembangunan sarana dan prasarana ekonomi. Ancaman kerusakan hutan mangrove semakin besar terjadi pada daerah yang dekat dengan pusat kegiatan ekonomi (Mukhlisi, 2017).

Ekosistem mangrove dapat dimanfaatkan tanpa merusak ekosistemnya dengan kegiatan berupa penelitian ilmiah, pendidikan, dan ekowisata. Pemanfaatan hutan mangrove sebagai tempat wisata merupakan suatu bentuk alternatif yang dapat dilakukan di wilayah pesisir. Adanya kawasan wisata alam atau ekowisata dapat memberikan manfaat ekonomis bagi pengelola dan masyarakat sekitar tanpa adanya kerusakan ekosistem mangrove. Selain itu ekowisata pada ekosistem mangrove merupakan salah satu upaya yang dapat dilakukan dalam rangka konservasi mangrove (Wibisono, 2004).

Ekowisata merupakan salah satu upaya pemerintah menghadirkan konsep wisata tanpa mengabaikan lingkungan (Wahyuni, et al. 2015). Kegiatan pariwisata berbasis wisata alam menjadi daya tarik wisatawan beberapa tahun terakhir.Daya dukung merupakan kemampuan wilayah dalam menampung sejumlah wisatawan dengan adanya keterbatasan sumber daya alam dan tidak merusak lingkungan sosial, budaya, dan ekonomi setempat dengan harapan dapat dipertahankan untuk generasi yang akan datang (Wibisono, 2004).

Salah satu wisata alam yang ada di wilayah pesisir Indonesia adalah Ekowisata mangrove Desa Kurau Kecamatan Koba, Kabupaten Bangka Tengah Propinsi Kepulauan Bangka Belitung. Hutan mangrove yang ada di Desa Kurau telah dijadikan kawasan ekowisata mangrove oleh masyarakat setempat. Mempertimbangkan keterbatasan tempat wisata dalam menampung jumlah pengunjung serta dampak yang ditimbulkan oleh pengunjung, maka perlu dilakukan kajian tentang kesesuaian dan daya dukung kawasan serta belum adanya penelitian terkait hal ini mendorong penilitian untuk mengkaji hal tersebut. Penelitian ini diharapkan dapat menjadi pendukung dalam pengelolaan dan pengembangan ekowisata mangrove Desa Kurau dan Desa Kurau Barat dalam menjaga kelestarian ekowisata Mangrove.

\section{METODOLOGI PENELITIAN}

Penelitian ini telah dilaksanakan pada bulan Maret 2019, di Kawasan Ekowisata Mangrove Desa Kurau dan Desa Kurau Barat Kecamatan Koba Kabupaten Bangka Tengah. Identifikasi sampel dilakukan di Laboratorium Fakultas Pertanian Perikanan dan Biologi, Universitas Bangka Belitung. 
Penelitian ini menggunakan data primer dan data sekunder. Data primer meliputi data kerapatan mangrove, data jenis biota, data jenis-jenis mangrove dan data kuesioner. Data sekunder didapat dari DKP Provinsi berupa data pasang surut.

\section{Kerapatan Jenis Mangrove dan Jenis Mangrove}

Kerapatan jenis menurut Masiyah dan Sunarni (2015) merupakan perbandingan antara jenis (ni) dengan jumlah luas total area pengambilan contoh (A). Hernandi et al. (2013) menyatakan bahwa data yang didapatkan yaitu data jenis tumbuhan dan jumlah individu setiap jenis. Noor et al. (2006) menyatakan bahwa data yang diambil berupa tumbuhan mangrove pada tingkat pohon dengan ukuran diameter $\geq 10 \mathrm{~m}$. Identifikasi mangrove dilakukan dengan cara sampel daun, buah, bunga, batang dan akar mangrove difoto setiap spesiesnya, kemudian diidentifikasi menggunakan buku panduan identifikasi mangrove dengan melihat ciri-ciri morfologi (bentuk luar seperti: warna dan bentuk) mangrove tersebut.

\section{ObJek Biota}

Data yang diambil berupa data nama jenis biota yang ada dikawasan ekowisata (Bahar, 2004), maka obyek biota akan dikelompokkan menjadi beberapa kategori antara lain Ikan, Udang, Kepiting, Moluska, Reptil, Burung dan lain-lain (Yulianda, 2007). Pengamatan biota dilakukan bersamaan dengan kegiatan sampling data tumbuhan mangrove dengan metode pengamatan langsung Setyawan et al. (2014) serta menyebarkan kuesioner kepada pengunjung dan pengurus kawasan wisata tersebut..

\section{Pasang Surut}

Pasang surut merupakan salah satu gejala alam, yaitu suatu gerakan vertikal (naik turunnya air laut secara teratur dan berulang-ulang) dari seluruh partikel massa air dari permukaan sampai bagian terdalam dari dasar laut (Surinati, 2007). Data pasang surut penelitian ini diperoleh dari DKP Provinsi Bangka Belitung. Data diolah dengan menjumlahkan angka pasang tertinggi dan angka surut terendah.

\section{Ketebalan Mangrove}

Ketebalan mangrove diukur berdasarkan panjang bentangan roll meter pada tiap stasiun secara tegak lurus dari batas darat sampai batas laut (Setiawan, 2013). Data ketebalan mangrove dihitung dengan menggunakan aplikasi Google Earth. Ketebalan mangrove dihitung dengan cara mengukur dari pertama kali mangrove ditemukan diarea pantai kearah daratan sampai terakhir kali mangrove ditemukan.

\section{Kuesioner}

Kuesioner adalah suatu teknik pengumpulan informasi yang memungkinkan analis mempelajari sikap-sikap, keyakinan, perilaku, dan karakteristik beberapa orang utama di dalam organisasi yang bisa terpengaruh oleh sistem yang diajukan atau oleh sistem yang sudah ada (Dewi et al. 2012). Pengambilan sampel menggunakan metode purposive sampling yaitu teknik pengambilan sampel oleh peneliti dengan pertimbangan tertentu dan Accidental Sampling yaitu pengambilan sampel dengan responden yang berada di area kawasan penelitian sesuai dengan konteks penelitian tersebut (Notoatmodjo, 2010). Ukuran sampel yang layak dalam penelitian adalah antara 30 sampai dengan 500 orang Sugiyono (2011). Berdasarkan Pertimbangan, peneliti mengambil jumlah responden secara kebetulan atau tidak sengaja bertemu dikawasan wisata tersebut dengan tidak melihat berapa jumlah laki-laki maupun jumlah perempuan, namun tetap mempertimbangkan usia responden yaitu>17 tahun, jenjang pendidikan responden minimal adalah Sekolah Menegah Pertama (SMP) dan juga masyarakat lokal yang selalu berpartispasi aktif dalam pengelolaan ekowisata mangrove dan berdomisili di Desa Kurau dan Desa Kurau Barat atau setidaknya Kecamatan Koba. Kemudian responden dari pihak pengelola 3 orang yang kesehariannya aktif turut mengelola ekowisata mangrove. Contoh kuesioner terdapat pada

\section{Lampiran 1.}

\section{Analisis Data}

\section{Analisis Kerapatan Jenis Mangrove}

Kerapatan jenis menurut Masiyah dan Sunarni (2015) merupakan perbandingan antara jenis (ni) dengan jumlah luas total area pengambilan contoh (A). Adapun analisis kerapatan mangrove dapat dilihat dengan rumus dibawah ini (Buwono, 2017):

Keterangan :

$$
\mathrm{Di}=\frac{\mathrm{ni}}{\mathrm{A}}
$$

Di : kerapatan jenis mangrove ke-i (ind $/ m^{2}$ )

ni : jumlah individu suatu jenis (ind)

A : luas total plot area $\left(\mathrm{m}^{2}\right)$

\section{Indeks Nilai Penting (INP)}

Indeks nilai penting adalah jumlah nilai kerapatan relatif (Rdi), frekuensi relatif (Rfi) dan penutup relatif (Rci)

$$
\mathrm{INP}=(\mathrm{Rdi}+\mathrm{Rfi}+\mathrm{Rci})
$$

Nilai penting suatu jenis berkisar antara $0 \%-300 \%$. Indeks nilai penting memberikan gambaran mengenai pengaruh atau peranan suatu jenis tumbuhan mangrove dalam komunitas mangrove. 


\section{Analisis Kesesuaian Wisata}

Wibisono (2004) menyatakan bahwa Analisis kesesuaian wisata adalah kegiatan penyesuaian potensi sumberdaya yang ada yang sesuai peruntukkannya. Matrik kesesuaian untuk wisata pantai kategori wisata mangrove dapat dilihat pada Tabel 1.

Tabel 1. Matrik kesesuaian untuk wisata pantai kategori wisata mangrove.

\begin{tabular}{|c|c|c|c|c|c|c|c|c|c|}
\hline Parameter & Bobot & Kategori S1 & Skor & Kategori S2 & Skor & Kategori S3 & Skor & Kategori N & Skor \\
\hline $\begin{array}{l}\text { Ketebalan } \\
\text { mangrove } \\
(\mathrm{m})\end{array}$ & 5 & $>500$ & 3 & $>200-500$ & 2 & $50-200$ & 1 & $<50$ & 0 \\
\hline $\begin{array}{c}\text { Jenis } \\
\text { mangrove } \\
\text { (ind) }\end{array}$ & 3 & $>5$ & 3 & $3-5$ & 2 & $1-2$ & 1 & 0 & 0 \\
\hline $\begin{array}{c}\text { Kerapatan } \\
\text { mangrove } \\
\left(\mathrm{m}^{2}\right)\end{array}$ & 3 & $>15-25$ & 3 & $10-15$ & 2 & $5-10$ & 1 & $<5$ & 0 \\
\hline $\begin{array}{l}\text { Pasang } \\
\text { surut } \\
(\mathrm{m})\end{array}$ & 3 & $0-1$ & 3 & $>1-2$ & 2 & $>2-5$ & 1 & $<5$ & 0 \\
\hline $\begin{array}{c}\text { Obyek } \\
\text { biota }\end{array}$ & 1 & $\begin{array}{l}\text { Ikan, } \\
\text { Udang, } \\
\text { Kepiting, } \\
\text { Moluska, } \\
\text { Reptil, } \\
\text { Burung }\end{array}$ & 3 & $\begin{array}{c}\text { Ikan, } \\
\text { Udang, } \\
\text { Kepiting, } \\
\text { moluska }\end{array}$ & 2 & $\begin{array}{c}\text { Ikan, } \\
\text { Moluska }\end{array}$ & 1 & $\begin{array}{c}\text { Salah } \\
\text { Satu } \\
\text { biota air }\end{array}$ & 0 \\
\hline $\begin{array}{c}\text { Biota } \\
\text { Berbahaya }\end{array}$ & 3 & Tidak ada & 3 & Tidak ada & 2 & Ular & 1 & $\begin{array}{l}\text { Ular, } \\
\text { Buaya }\end{array}$ & 0 \\
\hline
\end{tabular}

Sumber : Yulianda, 2007; Ramadhan et al. 2014.

Yulianda (2007) menyatakan bahwa rumus untuk menghitung indeks kesesuaian wisata yaitu :

Keterangan :

$$
\mathrm{IKW}=\sum\left[\frac{\mathrm{Ni}}{\mathrm{N} \text { maks }}\right] \times 100 \%
$$

IKW : Indeks Kesesuaian Wisata

$\mathrm{Ni} \quad$ : Nilai parameter ke-i (Bobot x Skor)

Nmaks : Nilai maksimum dari suatu kategori wisata

Klasifikasi untuk indeks kesesuaian wisata mangrove yang diperoleh adalah :

S1 : Sangat sesuai, dengan nilai $83-100 \%$

S2 : Sesuai, dengan nilai $50-<83 \%$

S3 : Sesuai bersyarat, dengan nilai $17-<50 \%$

$\mathrm{N} \quad$ : Tidak sesuai, dengan nilai $<17 \%$

Analisis Daya Dukung Wisata

DDK (Daya Dukung Kawasan) adalah jumlah maksimum pengunjung yang secara fisik dapat ditampung di kawasan yang disediakan pada waktu tertentu tanpa menimbulkan gangguan pada alam dan manusia. Perhitungan DDK menggunakan rumus berikut (Yulianda, 2007) :

Keterangan :

$$
\mathrm{DDK}=\mathrm{k} \times \frac{L p}{L t} \times \frac{W t}{W p}
$$

DDK : Daya Dukung Kawasan (orang/hari)

$\mathrm{K} \quad$ : Potensi ekologis pengunjung persatuan unit area (orang)

Lp : Luas/Panjang area yang dapat dimanfaatkan (m)

Lt : Unit area untuk kategori tertentu $(\mathrm{m})$

Wt : Waktu yang disediakan oleh kawasan untuk kegiatan wisata dalam satu hari (jam) 
Wp : Waktu yang dihabiskan oleh pengunjung untuk setiap kegiatan tertentu (jam)

\section{Analisis Penentuan Jumlah Responden}

Penentuan jumlah responden pada penelitian ini sesuai dengan jumlah pengunjung sebelumnya. Adapun penentuan jumlah responden pada penelitian ini mengacu pada rumus Fauzi (2011) sebagai berikut :

Keterangan :

$$
n=\frac{N \cdot Z^{2} \cdot 0,25}{\left[d^{2}(N-1)+\left[Z^{2} \cdot 0,25\right]\right.}
$$

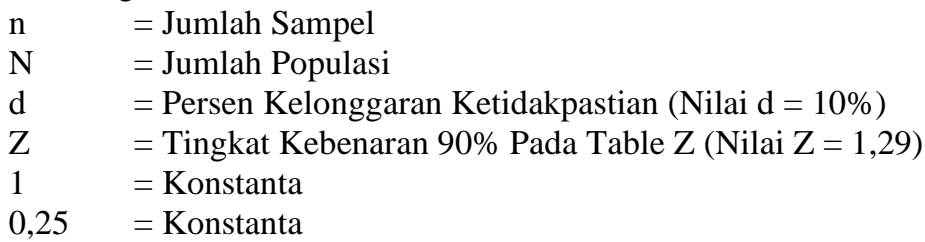

\section{HASIL DAN PEMBAHASAN}

Ketebalan Mangrove

Hasil pengukuran ketebalan mangrove di lokasi penelitian Ekowisata Mangrove Desa Kurau memiliki nilai sebesar 437,19 m, dan di Ekowisata Mangrove Desa Kurau Barat memiliki nilai sebesar 1.109,15 m. Hasil analisis ketebalan mangrove menggunakan Google Earth dapat dilihat pada Gambar 1.

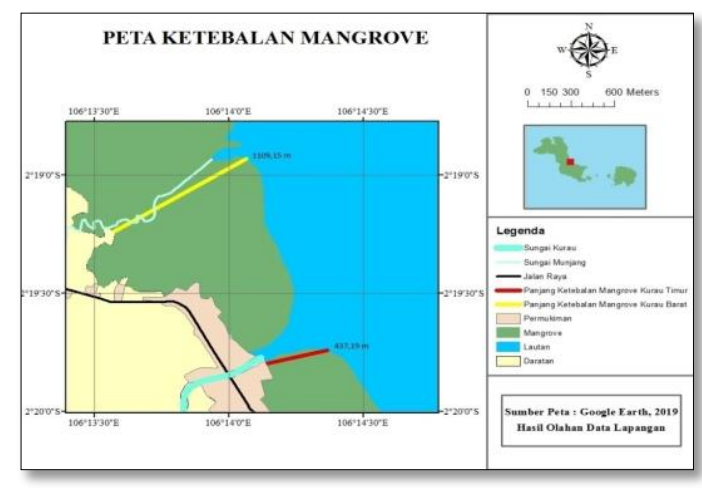

Gambar 1. Peta Ketebalan Mangrove

\section{Komposisi jenis}

. Hasil jenis mangrove yang ditemukan di lokasi penelitian disajikan pada Tabel 2.

Tabel 2. Jenis-jenis mangrove yang ditemukan di Ekowisata Mangrove Desa Kurau dan Desa Kurau Barat

\begin{tabular}{ccccc}
\hline No. & Nama Spesies & Nama Lokal & Desa Kurau Barat & Desa Kurau \\
\hline 1 & Rhizophora apiculata & Bakau minyak & + & + \\
2 & Xylocarpus granatum & Nyireh & + & - \\
3 & Rhizophora mucronata & Bakau hitam & + & + \\
4 & Excoeceria agallocha & Buta-buta & + & - \\
5 & Heritiera littoralis & Tidak diketahui & + & - \\
6 & Avicenia alba & Api-api & + & + \\
7 & Bruguiera sexangula & Mata buaya & + & + \\
8 & Soneratia alba & Pedada & - & + \\
9 & Nypah fruticans & Nipah & + & + \\
\hline
\end{tabular}

Kerapatan Jenis Mangrove dan Indeks Nilai Penting

Tabel 3.

Nilai kerapatan jenis mangrove di Desa Kurau dan Desa Kurau Barat Kabupaten Bangka Tengah disajikan pada

Tabel 3. Nilai kerapatan jenis dan Indeks Nilai Penting yang ditemukan di ekosistem Mangrove Desa Kurau dan Desa Kurau Barat

\begin{tabular}{lll}
\hline Nama Spesies & Ekowisata Mangrove Kurau & Ekowisata Mangrove Munjang \\
\hline
\end{tabular}




\begin{tabular}{ccccc}
\cline { 2 - 5 } & $\mathrm{Di}$ & $\mathrm{INP}$ & $\mathrm{Di}$ & INP \\
\hline Avicenia alba & - & - & 0,444 & 10,064 \\
Bruguiera sexangula & 0,111 & 12,320 & 2,667 & 37,436 \\
Excoecaria agallocha & - & - & 3 & 26,522 \\
Heritiera littoralis & - & - & 0,889 & 12,336 \\
Rhizophora apiculata & 6,778 & 169,231 & 9,333 & 118,302 \\
Rhizophora mucronata & 3,778 & 61,652 & 1,222 & 32,911 \\
Sonneratia alba & 2 & 56,797 & - & - \\
Xylocarpus granatum & - & - & 4,667 & 62,430 \\
\hline Total & 12,67 & 300 & 22,22 & 300 \\
\hline
\end{tabular}

\section{Jenis Biota}

Hasil penelitian dan identifikasi jenis biota di lokasi penelitian dapat dilihat pada Tabel 4.

Tabel 4. Obyek biota yang ditemukan di ekosistem mangrove Desa Kurau dan Desa Kurau Barat

\begin{tabular}{ccccc}
\hline No. & Kelompok & Nama Spesies & Desa Kurau Barat & Desa Kurau \\
\hline 1 & Moluska & Telescopium $s p$ & + & - \\
2 & Moluska & Nassarius $s p$ & + & - \\
3 & Moluska & Nerita $s p$ & - & + \\
4 & Moluska & Tiara $s p$ & - & + \\
5 & Moluska & Terebralia $s p$ & - & + \\
6 & Moluska & Polymesoda erosa & - & + \\
7 & Reptil & Varanus sp & + & + \\
8 & Reptil & Malayophyton reticulates & + & - \\
9 & Pisces & Orheocromis niloticus & + & - \\
10 & Pisces & Periothalamus sp & - & + \\
11 & Mamalia & Macaca sp & + & - \\
12 & Krustasea & Uca sp & + & + \\
13 & Krustasea & Scylla serrate & + & + \\
\hline
\end{tabular}

Pasang Surut

Data pasang surut didapatkan dari Boost Center stasiun Tanjung Pesona, Kabupaten Bangka selama 1 bulan yang didapatkan dari Boost Center dapat dilihat pada Gambar 2.

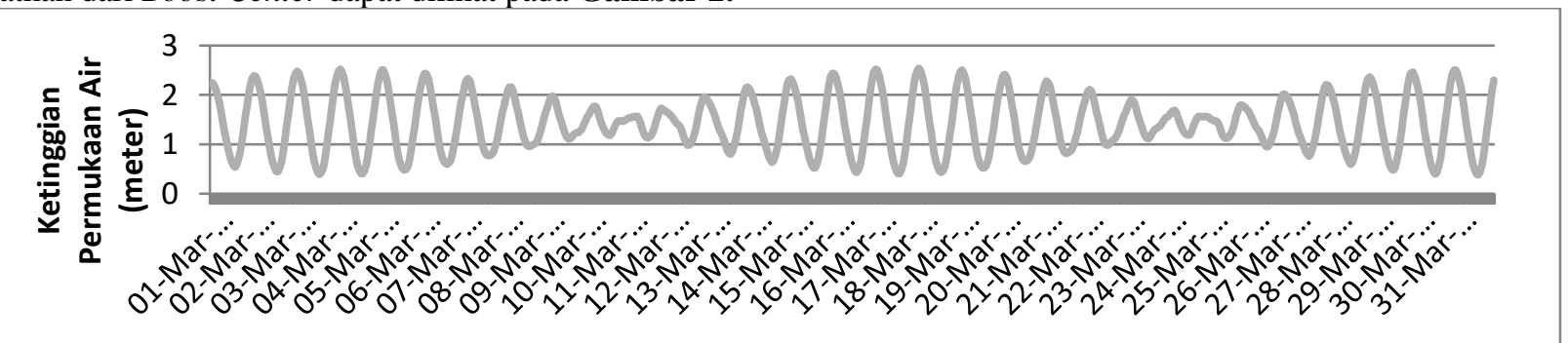

Gambar 2. Kondisi pasang surut selama bulan Maret 2019 (sumber: Boost Center)

Indeks Kesesuaian Wisata

Indeks Kesesuaian Wisata berdasarkan hasil penelitian pada masing-masing stasiun pengamatan yang ada di Desa Kurau dan Desa Kurau Barat dapat dilihat pada Tabel 5.

Tabel 5. Indeks Kesesuaian Wisata Kategori Wisata Mangrove

\begin{tabular}{cccccccc}
\hline Parameter & \multirow{2}{*}{ Bobot } & \multicolumn{3}{c}{ Desa Kurau } & \multicolumn{3}{c}{ Desa Kurau Barat } \\
\cline { 2 - 8 } & Skor & Kategori & Jumlah & Skor & Kategori & Jumlah \\
\hline $\begin{array}{c}\text { Ketebalan } \\
\text { Mangrove }(\mathrm{m})\end{array}$ & 5 & 3 & 437,19 & 15 & 3 & 1109,15 & 15 \\
$\begin{array}{c}\text { Jenis Mangrove } \\
\quad \text { (ind) }\end{array}$ & 3 & 3 & $>5$ & 9 & 3 & $>5$ & 9 \\
$\begin{array}{c}\text { Kerapatan } \\
\text { Mangrove }\left(m^{2}\right)\end{array}$ & 3 & 2 & $10-15$ & 6 & 3 & $>15-25$ & 9
\end{tabular}




\begin{tabular}{|c|c|c|c|c|c|c|c|}
\hline \multirow{2}{*}{ Parameter } & \multirow{2}{*}{ Bobot } & \multicolumn{3}{|c|}{ Desa Kurau } & \multicolumn{3}{|c|}{ Desa Kurau Barat } \\
\hline & & Skor & Kategori & Jumlah & Skor & Kategori & Jumlah \\
\hline Pasang Surut (m) & 1 & 1 & 2.16 & 1 & 1 & 2.16 & 1 \\
\hline Objek Biota & 1 & 3 & $\begin{array}{l}\text { Ikan, } \\
\text { Udang, } \\
\text { Kepiting, } \\
\text { Moluska, } \\
\text { Reptil, } \\
\text { Burung }\end{array}$ & 3 & 3 & $\begin{array}{l}\text { Ikan, } \\
\text { Udang, } \\
\text { Kepiting, } \\
\text { Moluska, } \\
\text { Reptil, } \\
\text { Burung }\end{array}$ & 3 \\
\hline Biota Berbahaya & 3 & 3 & Tidak ada & 9 & 1 & Ular & 3 \\
\hline Total & & & 43 & & & 40 & \\
\hline IKW & & & $89,58 \%$ & & & $83,33 \%$ & \\
\hline Kategori & & & S1 & & & S1 & \\
\hline
\end{tabular}

Daya Dukung Kawasan

Hasil daya dukung kawasan di lokasi peneltian dapat dilihat pada Tabel 6.

Tabel 6. Daya Dukung Kawasan wisata Mangrove Desa Kurau dan Mangrove Desa Kurau Barat

\begin{tabular}{ccccccc}
\hline \multirow{2}{*}{ Lokasi } & \multicolumn{5}{c}{ Parameter } & Hasil \\
\cline { 2 - 7 } & $\mathrm{K}$ & $\mathrm{Lp}$ & $\mathrm{Lt}$ & $\mathrm{Wt}$ & $\mathrm{Wp}$ & DDK \\
\hline Desa Kurau Barat & 1 & $400 \mathrm{~m}$ & $50 \mathrm{~m}$ & $10 \mathrm{jam}$ & $1.5 \mathrm{jam}$ & 44 \\
Desa Kurau & 1 & $500 \mathrm{~m}$ & $50 \mathrm{~m}$ & 11 jam & $2 \mathrm{jam}$ & 55 \\
\hline
\end{tabular}

\section{Pembahasan}

\section{Deskripsi Lokasi Penelitian}

Desa Kurau terletak di Kabupaten Bangka Tengah Kecamatan Koba Provinsi Kepulauan Bangka Belitung. Desa Kurau saat ini telah terbagi atas 2 Desa yaitu Desa Kurau Barat dan Desa Kurau yang dihubungkan oleh jembatan Kurau. Desa Kurau (Timur) memiliki tempat wisata mangrove yang terletak di sebelah TPI Kurau dan dermaga keberangkatan menuju wisata Pulau Ketawai. Wisata mangrove memiliki jembatan (track area) yang sangat panjang untuk pengunjung menikmati dan mengambil foto kenangan ataupun melihat lihat berbagai jenis mangrove dan satwa-satwa yang ada didalamnya. Daya tarik dari ekowisata Mangrove Desa Kurau ini yaitu adanya monyet yang biasanya dipanggil Jabrik oleh pengunjung

Desa Kurau Barat memilki ekowisata mangrove yang terletak di daerah Munjang, yaitu wisata mangrove Munjang. Mangrove Munjang merupakan wisata yang dikelola oleh kelompok masyarakat setempat. Fasilitas Wisata Mangrove Munjang menjadi daya tarik pengunjung, yaitu untuk mendatangi kawasan mangrove tersebut pengunjung bisa menyewa boat yang telah disediakan oleh pengurus wisata dengan membayar 10.000/orang, ataupun pengunjung bisa berjalan kaki menuju area mangrove dikarenakan lokasi ekowisata yang lumayan jauh yakni dengan jarak kurang lebih 200 meter. Wisata mangrove Kurau Barat juga menyediakan sepeda gantung, Flying fox dan pondok-pondok istirahat untuk wisatawan.

\section{Komunitas Mangrove \\ Ketebalan Mangrove}

Ketebalan vegetasi mangrove pada lokasi penelitian ekowisata Mangrove Desa Kurau memiliki ketebalan 437,19 m. sedangkan Lokasi penelitian Desa Kurau Barat didapatkan ketebalan mangrove mencapai 1109,15 m. Rendahnya ketebalan mangrove Di Desa Kurau dikarenakan Lokasi penelitian berhadapan langsung dengan laut, sehingga zona mangrove mayor akan terendam air jika pasang normal. Lokasi wisata ini sendiri dekat dengan pemukiman warga dan tempat pelelangan ikan, sedangkan lokasi ekowisata mangrove Desa Kurau Barat juga berada tidak jauh dari pemukiman warga, namun lokasi ini letaknya agak tertutup. Lokasi yang berada disekitar pemukiman warga menyebabkan mangrove mengalami tekanan akibat kegiatan warga setempat seperti penebangan liar, pembuangan sampah sembarangan dan lain sebagainya.

Wardhani (2011) menyatakan bahwa pertumbuhan penduduk yang tinggi dan pesatnya kegiatan pembangunan didaerah pesisir dengan berbagai peruntukan misalnya seperti pemukiman, perikanan, pelabuhan, maka akan terjadi tekanan ekologis terhadap ekosistem pesisir, khususnya tekanan pada ekosistem mangrove juga akan meningkat yang berdampak akibat kegiatan warga setempat seperti pembuangan sampah sembarangan, karena dilihat pada lokasi penelitian banyaknya sampah di area mangrove tersebut.

\section{Komposisi Jenis}

Jenis mangrove yang didapatkan pada lokasi Mangrove Desa Kurau berjumlah 6 jenis dan pada lokasi Mangrove Desa Kurau Barat bejumlah 9 jenis (Tabel 2). Yulianda (2007) menjelaskan bahwa pada kategori jenis mangrove, untuk mangrove Desa Kurau adalah sangat baik karena berjumlah lebih dari 5 jenis dan pada lokasi mangrove Desa Kurau Barat 
termasuk dalam kategori sangat baik juga karena jumlahnya lebih dari 5 jenis. Mangrove yang terdapat pada penelitian ini terdapat mangrove sejati (mayor) mangrove penunjang (minor) dan mangrove asosiasi. Perhitungan pada penelitian ini hanya terfokus pada mangrove mayor saja dikarenakan jumlah mangrove mayor yang sangat mendominasi pada lokasi penelitian.

Jenis mangrove pada lokasi Desa Kurau Barat lebih banyak jika dibandingkan dengan lokasi Desa Kurau dikarenakan tingkat kerapatan dan ketebalan mangrove pada lokasi penelitian Desa Kurau Barat lebih tinggi dari pada lokasi penelitian Desa Kurau. Lokasi penelitian Desa Kurau memiliki jenis mangrove yang sedikit dibandingkan dengan Lokasi penelitian Desa Kurau Barat dikarenakan mangrove Desa Kurau dekat dengan pemukiman dan kegiatan perikanan, hal ini sangat berpengaruh pada mangrove akibat perkembangan kegiatan pembangunan yang pesat, mangrove dapat mangalami kerusakan akibat kegiatan pembuangan sampah sembarang, pembuangan limbah dan penebangan liar yang juga sangat berpengaruh pada penurunan jumlah jenis mangrove pada suatu ekosistem. Noor et al, (2006) menyatakan bahwa rusaknya area mangrove akan mengakibatkan hilangnya jenis-jenis tumbuhan mengrove. Kegiatan pembangunan yang dilaksanakan dengan pesat dan area mangrove merupakan salah satu objek konversi juga sangat berpengaruh pada keberadaan jenis-jenis mangrove pada suatu komunitas.

\section{Kerapatan Jenis dan Indeks Nilai Penting}

Kerapatan jenis mangrove Desa Kurau sebesar $13 \mathrm{ind} / \mathrm{m}^{2}$ (pembulatan dari nilai 12,67 ind $/ \mathrm{m}^{2}$ ) dan kerapatan jenis mangrove Desa Kurau Barat sebesar $23 \mathrm{ind} / \mathrm{m}^{2}$ (pembulatan dari nilai $22.22 \mathrm{ind} / \mathrm{m}^{2}$ ). Menurut Yulianda (2007) nilai kerapatan mangrove pada lokasi penelitian Desa Kurau masuk kedalam kategori sesuai (S2) sedangkan nilai kerapatan jenis mangrove pada lokasi penelitian Desa Kurau Barat memiliki kerapatan sangat sesuai (S1).

Lokasi penelitian Desa Kurau Barat memiliki kerapatan lebih tinggi dibandingkan dengan lokasi penelitian Desa Kurau dikarenakan perbedaan tingkat kerapatan memperlihatkan bahwa pola adaptasi setiap individu mangrove berbedabeda, dapat dipengaruhi oleh banyak faktor. Kerapatan yang rendah pada lokasi penelitian Desa Kurau juga dipengaruhi oleh pembangunan yang pesat dari pemukiman dan sektor perikanan, sangat mempengaruhi kerapatan jenis mangrove dikarenakan dampak negative yang diberikan seperti penebangan liar, pembuang sampah dan limbah dari sektor perikanan. Noor et al. (2006) menyatakan bahwa zonasi mangrove juga merupakan faktor yang mempengaruhi perbedaan tingkat kerapatan suatu kawasan mangrove. Pemanfaatan mangrove secara tradisional oleh masyarakat sangat berpengaruh pada pertumbuhan mangrove.

Hasil perhitungan Indeks Nilai Penting berdasarkan kategori pohon pada lokasi Mangrove Desa Kurau dan Desa Kurau Barat, jenis mangrove Rhizophora apiculata memiliki nilai INP tertinggi jika dibandingkan dengan jenis lainnya dengan nilai Desa Kurau sebesar 169,231 \% dan Desa Kurau Barat sebesar 118,302\% dikarenakan jenis mangrove Rhizophora apiculata memiliki tingkat kompetisi yang tinggi dibandingkan dengan jenis mangrove lainnya. Rhizophora apiculata berada pada zonasi mayor pada sebuah komunitas mangrove dikarenakan memiliki perakaran yang kuat sebagai penahan gelombang. Hal ini sesuai dengan Parmadi et al, (2016) yang menyatakan bahwa jenis Rhizophora apiculata memiliki tingkat kompetisi yang besar untuk mendapatkan unsur hara dan cahaya matahari.

Nilai kerapatan mangrove pada lokasi Desa Kurau Barat lebih tinggi jika dibandingkan dengan nilai kerapatan mangrove Desa Kurau yang seharusnya memiliki indeks nilai penting suatu spesies lebih tinggi pula. Jenis substrat untuk pertumbuhan mangrove berpengaruh pada indeks nilai penting jenis mangrove. Hal ini dapat dilihat pada penelitian sebelumnya yaitu Savira et al. (2018) yang menyatakan bahwa substrat pada mangrove Desa Kurau merupakan substrat berlumpur dan subtrat mangrove Desa Kurau Barat merupakan substrat lumpur kasar yang berarti bahwa mangrove jenis Rhizophora apiculata dapat hidup lebih baik pada substrat berlumpur yang memiliki unsur hara tinggi jika dibandingkan dengan substrat berlumpur kasar yang memiliki unsur hara rendah. hal ini menunjukkan bahwa tingginya nilai INP Rhizophora apiculata dikedua lokasi penelitian dikarenakan jenis mangrove Rhizophora apiculata dapat tumbuh pada tanah bertekstur halus dan memiliki bahan organik yang lebih tinggi (Barkey (1990) dalam Savira et al. (2018)).

\section{Jenis Biota}

Obyek biota merupakan salah satu penunjang daya tarik wisata mangrove selain jenis-jenis mangrove itu sendiri. Pengambilan objek biota diamati secara langsung dilapangan, seperti ikan, kepiting, moluska, burung, reptil dan lain sebagainya. Berdasarkan hasil penelitian obyek biota disajikan pada Tabel 4. Menurut parameter kesesuaian wisata mangrove Yulianda (2007) jenis biota yang ditemukan masuk kedalam kategori sangat sesuai (S1).Jenis biota yang beragam tergantung pada keadaan komunitas mangrove. Hasil penelitian bahwa kondisi mangrove di lokasi penelitian Desa Kurau dan lokasi penelitian Desa Kurau Barat tergolong baik dilihat dari nilai kerapatan dan ketebalan mangrove berdasarkan parameter kesesuaian kategori mangrove. Mangrove memiliki produktivitas yang baik dan merupakan produsen pada rantai makanan yang berarti bahwa biota yang berasosiasi didalamnya sangat bergantung pada ekosistem mangrove. Biota memanfaatkan mangrove sebagai tempat perlindungan, pemijahan, pembesaran dan sebagai tempat mencari makan.

Karimah (2007) menyatakan bahwa hutan mangrove merupakan habitat penting bagi hewan laut. Umumnya didominasi oleh kelompok krustasea dan moluska. Imran dan Efendi (2016) menyatakan bahwa ekosistem mangrove 
merupakan salah satu ekosistem yang memiliki produktivitas tinggi dengan dekomposisi bahan organik yang tinggi, sehingga menjadikannya mata rantai ekologis yang sangat penting bagi kehidupan mahkluk hidup yang berada diperairan sekitarnya.

Biota yang ditemukan di lokasi penelitian menjadi daya tarik yang sangat mencolok pada ekowisata mangrove terutama kehadiran monyet dan ikan gelodok (saat air surut ikan akan nampak jelas) pada lokasi Mangrove Kurau. Secara tidak langsung pengunjung akan tertarik melihat atau mempelajari tingkah laku biota mangrove, pengunjung yang penasaran akan mendekati biota dan terkadang akan berinteraksi langsung dengan biota seperti saat pengunjung memberi makan biota-biota mangrove tersebut. Pengunjung akan mendapatkan banyak pengalaman menarik dan ilmu yang sangat bermanfaat dari kehadiran biota-biota mangrove, hal ini sesuai dengan Damanik dan Weber (2006) yang menyatakan bahwa salah satu dari konsep dasar ekowisata yakni wisatawan yang berwisata bisa melakukan sesuatu yang berguna untuk memberikan perasaan senang dan bahagia yang bersumber dari fasilitas rekreasi. Menurut Yulianda (2007) hasil penelitian biota yang ditemukan di kedua lokasi penelitian seperti burung, reptil, moluska, kepiting dan biota lainnya masuk kategori sangat sesuai menurut indeks kesesuaian wisata kategori mangrove, namun Desa Kurau Barat terdapat biota berbahaya yaitu ular sanca (Malayophyton reticulates). Menurut penjelasan (wawancara) pengelola wisata, ular tersebut tidak mengganggu pengunjung yang datang ke lokasi tersebut dikarenakan ular tersebut dalam keadaan tidur dan akan beraktivitas pada malam hari (nocturnal).

\section{Pasang Surut}

Data pasang surut menggunakan data sekunder yang didapatkan dari Boost Center stasiun Tanjung Pesona Kabupaten Bangka selama 1 bulan. Analisis pasang surut memperlihatkan bahwa tinggi muka air dilokasi penelitian dari data Boost Center dapat dilihat pada Gambar 2. Kondisi muka air pasang surut pada saat pasang tertinggi dengan ketinggian $2.54 \mathrm{~m}$ sedangkan tinggi air pada saat surut terendah yaitu $0.38 \mathrm{~m}$. Selisih dari pasang surut ini menunjukkan bahwa kisaran pasang surut yang diperoleh adalah sebesar $2.16 \mathrm{~m}$. Yulianda (2007) menyatakan bahwa kisaran pasang surut dilokasi penelitian adalah kategori sesuai bersyarat untuk pemilihan lokasi wisata mangrove dengan mempertimbangkan keamanannya. Kondisi ini sangat berpengaruh pada akses menuju ekowisata mangrove, mengingat tracking area ekowisata Mangrove Desa Kurau maupun ekowisata Mangrove Desa Kurau Barat berada diatas perairan jika terjadi pasang dan berpengaruh pula pada pada habitat mangrove. Tracking area bisa disiasati dengan membangun tracking area yang agak tinggi.

\section{Indeks Kesesuaian Wisata}

Hasil penelitian pada lokasi ekowisata mangrove Desa Kurau, didapatkan hasil nilai skor total sebesar 43 dari skor maksimum 48 dan nilai Indeks Kesesuaian Wisata 89,58\%, angka tersebut masuk kedalam kategori sangat sesuai, sedangkan hasil penelitian pada lokasi ekowisata mangrove Desa Kurau Barat, nilai skor total sebesar 40 dari skor maksimum 48 dan nilai Indeks Kesesuaian Wisata 83,33\%, yaitu masuk kedalam kategori sangat sesuai. Kelayakan wisata mangrove dengan mempertimbangkan beberapa parameter yaitu ketebalan mangrove, kerapatan mangrove, pasang surut, jenis-jenis mangrove, objek biota dan biota berbahaya dapat dilihat pada Tabel. $\mathbf{5}$.

Lokasi mangrove Desa Kurau berdasarkan parameter penelitian didapatkan : nilai ketebalan 437,19 m (sesuai), kerapatan $13 \mathrm{ind} / \mathrm{m}^{2}$ (sesuai), jenis mangrove 6 ind (sangat sesuai), objek biota 8 ind (sangat sesuai), pasang surut $2.145 \mathrm{~m}$ (sesuai bersyarat), tidak terdapat biota berbahaya (sangat sesuai), sedangkan lokasi mangrove Desa Kurau Barat berdasarkan parameter penelitian didapatkan : nilai ketebalan $1.109,15 \mathrm{~m}$ (sangat sesuai), kerapatan $23 \mathrm{ind} / \mathrm{m}^{2}$ (sangat sesuai), jenis mangrove 9 ind (sangat sesuai), objek biota 8 ind (sangat sesuai), pasang surut 2,16 $\mathrm{m}$ (sesuai bersyarat), biota berbahaya merupakan ular (sesuai bersyarat).

Pengembangan wisata mengacu pada parameter ketebalan, kerapatan, jenis mangrove, pasang surut, objek biota dan biota berbahaya. Skor ketebalan, kerapatan mangrove, jenis mangrove, objek biota mangrove memiliki skor tertinggi dimana menunjukkan mangrove yang sangat baik dijadikan sebagai tempat ekowisata. Kegiatan wisata alam yang menarik membutuhkan dukungan dari alam itu pula, seperti keadaan lingkungan yang harus baik, biota yang beragam dan tidak berbahaya bagi pengunjung, jenis mangrove yang beragam agar dapat sekaligus dijadikan sebagai wisata edukasi. Damanik dan Weber (2006) menyatakan bahwa aspek lingkungan yang alamiah pada produk wisata menjadi incaran, aspek estetika,

Berdasarkan data IKW yang didapatkan berdasarkan perhitungan dengan mempertimbangkan beberapa parameter kesesuaian wisata kategori wisata mangrove didapatkan nilai IKW yang sangat sesuai dengan parameter yang ada dimana ekosistem mangrove yang masih asri dan terjaga meskipun dekat dengan aktifitas warga setempat. Hal ini tidak jauh berbeda dengan hasil penelitian (Wibowo, 2015), bahwa kesesuaian kawasan ekowisata mangrove di Kecamatan Kampung Melayu Kota Bengkulu memiliki nilai Indeks Kesesuian Wisata sebesar $79 \%$ yaitu masuk kategori sangat sesuai. Pengelolaan ekowisata akan sangat baik jika didasarkan pada pengelolaan pembangun pariwisata berkelanjutan yang berdasar pada konsep ekowisata yaitu menyelaraskan antara pengelolaan lingkungan hidup, pengelolaan ekosistem dan pembangunan ekowisata mangrove.

\section{Daya Dukung Kawasan}


Setyawan (2014) menjelaskan bahwa analisis daya dukung diperlukan dalam pemanfaatan secara lestari potensi sumberdaya pesisir untuk pengembangan wisata bahari. Mengingat tingkat kerentanan dan ruang yang terbatas untuk pengunjung maka perlu ditentukan daya dukung kawasan. Berdasarkan hasil perhitungan yang telah dilakukan didapatkan nilai daya dukung untuk ekowisata mangrove kurau sebesar 55 orang perhari, rata-rata waktu yang dihabiskan pengunjung selama 2 jam, waktu yang disediakan oleh kawasan dalam satu hari selama 11 jam, panjang track yang dimanfaatkan yaitu 500 meter dengan luas area mangrove yang telah digunakan yaitu 5 hektar dari 250 hektar, sedangkan ekowisata mangrove Desa Kurau Barat sebesar 44 orang perhari, rata-rata waktu yang dihabiskan pengunjung selama 2 jam, waktu yang disediakan oleh kawasan dalam satu hari selama 11 jam, panjang track yang dimanfaatkan yaitu 400 meter dengan luas area mangrove yang dimanfaatkan yaitu 3 hektar.

Pembatasan jumlah pengunjung juga memiliki peran penting bagi pengelola untuk membuat nyaman pengunjung yang datang untuk memberikan image positive bagi pengelola. Murtini (2017) menjelaskan bahwa semakin bertambahnya jumlah wisatawan tentunya semakin mengurangi kenyamanan, sementara itu faktor kenyamanan mempunyai peran penting bagi wisatawan yang berada di suatu lokasi obyek wisata. Melalui penghitungan daya dukung, pengelola dapat secara bijak membatasi jumlah wisatawan ketika jumlah wisatawan sudah melebihi ambang batas maksimal.

Berdasarkan hasil kuesioner jumlah pengunjung yang berkunjung dihari-hari biasa pada lokasi Desa Kurau sekitar 50-55 orang/hari sedangkan pada hari libur sekitar 90-110 orang/hari, sedangkan Lokasi Mangrove Desa Kurau Barat jumlah pengunjung yang berkunjung dihari-hari biasa sekitar 55-100 orang/hari sedangkan pada hari libur sekitar 400-550 orang/hari. Berdasarkan dari hasil wawancara pengelola mangrove Desa Kurau, pengunjung yang datang ketempat ekowisata Mangrove Desa Kurau akan bertambah jika ada pengunjung yang akan berkunjung ke Pulau Ketawai untuk sekedar melihat-lihat kawasan ekowisata ataupun sengaja ingin mendatangi kedua tempat wisata tersebut dikarenakan dermaga keberangkatan ke Pulau Ketawai berada disamping kawasan Ekowisata Mangrove Desa Kurau dengan jumlah pengunjung yang tidak terduga. Melihat dari nilai pengunjung yang datang ketempat wisata pada hari libur pada setiap lokasi telah melewati batas perhitungan daya dukung kawasan, sehingga perlu dilakukan suatu strategi untuk meminimalisir kerusakan lingkungan akibat kedatangan pengunjung. Strategi yang dapat dilakukan yakni dengan menambahkan tracking area dengan tidak merusak alam (dalam hal ini yaitu penebangan pohon mangrove), pengadaan kembali tiket masuk dengan nilai jual saat hari libur diberikan tarif lebih tinggi dibandingkan dengan tarif tiket dihari-hari biasa, penambahan serta peletakan tempat sampah yang strategis agar pengunjung tidak merusak alam dengan membuang sampah sembarangan, dilakukannya denda jika mengetahui ada pengunjung yang membuang sampah sembarangan ataupun mengganggu biota-biota yang ada ekosistem mangrove.

\section{SIMPULAN DAN SARAN}

\section{Simpulan}

Penelitian tentang Kesesuaian dan Daya Dukung Kawasan di Desa Kurau dan Desa Kurau Barat Kabupaten Bangka Tengah dapat disimpulkan bahwa:

1. Ekowisata Mangrove Desa Kurau tergolong kedalam kategori S1 (sangat sesuai) dengan nilai rata-rata 89,58\%. Nilai parameter yang tergolong S1 (sangat sesuai) meliputi ketebalan mangrove 437,19 m, jenis mangrove 6 individu, kerapatan mangrove $13 \mathrm{ind} / \mathrm{m}^{2}$, pasang surut $2,16 \mathrm{~m}$, objek biota, dan tidak terdapat biota berbahaya. Lokasi ekowisata mangrove Desa Kurau Barat tergolong kategori S1 (sangat sesuai) dengan nilai rata-rata 83,33\%. Nilai parameter yang tergolong S1 (sangat sesuai) meliputi ketebalan mangrove $1109,15 \mathrm{~m}$, jenis mangrove 9 individu, kerapatan mangrove $23 \mathrm{ind} / \mathrm{m}^{2}$, pasang surut $2,16 \mathrm{~m}$, objek biota, dan terdapat biota berbahaya yaitu ular sanca.

2. Ekowisata mangrove Desa Kurau memiliki luas area yang dapat dimanfaatkan yaitu $55 \mathrm{orang} / \mathrm{hari}$, sedangkan lokasi ekowisata Mangrove Munjang Desa Kurau Barat memiliki luas area yang dapat dimanfaatkan yaitu 44 orang/hari. Dibandingkan dengan hasil penelitian jumlah pengunjung ekowisata Mangrove Kurau Desa Kurau sudah melampaui batas daya dukung kawasan sehingga perlu dilakukan strategi-strategi guna mengatasi dampak yang ditimbulkan Saran akibat pengunjung yang berlebih.

Saran dari penelitian ini yaitu diberikan kepada masyarakat sekitar untuk menjaga alam dan tidak melakukan penebangan liar dan mendukung kegiatan positif tentang pengembangan pengelolaan wisata mangrove. Saran yang diberikan kepada pemerintah setempat agar memberi arahan mengenai pengelolaan berkelanjutan.

\section{DAFTAR PUSTAKA}

Anwar, Hairil dan H. Chafid Fandeli 2007. Analisis pengelolaan ekowisata di zone pemanfaatan Taman Nasional Gunung Rinjani. [Dissertasi]. Universitas Gadjah Mada.

Bahar, A. 2004, Kajian Kesesuaian dan Daya Dukung EkosistemMangrove untuk Pengembangan Ekowisata di Gugus Pulau Tanakeke Kabupaten Takalar Sulawesi Selatan. [Tesis]. Institut Pertanian Bogor.

Buwono, R. Y. 2017. Identifikasi dan Kerapatan Ekosistem Mangrove di Kawasan Teluk Pangpang Kabupaten Banyuwangi. Samakia : Jurnal Ilmu Perikanan, 8 (1) : 32-37 Damanik Janianton dan Helmut Weber. 2006. Perencanaan Ekowisata Dari Teori ke Aplikasi. Yogyakarta : Andi Offset. 
Damanik, J dan Weber, H. 2006. Perencanaan Ekowisata Dari Teori ke Aplikasi. Yogyakarta : Andi Offset.

Dewi R S, Ali H N dan Astuti H M. 2012. Analisis Pengaruh Kualitas Informasi pada Kuesioner Indeks Pengajaran Dosen Online terhadap Kepuasan Pengguna Studi Kasus : Fakultas Teknologi Informasi ITS. Jurnal Teknik ITS. 1 (1) : 345-351.

Fachrul, M. F. 2007. Metode Sampling Bioekologi. Jakarta. Bumi Askara.

Fandeli, C. 2000. Pengertian Dan Konsep Dasar Ekowisata. Fakultas Kehutanan Universitas Gadjah Mada Yogyakarta.

Fauziah, P., dan Siddiq, S. S. 2017. Strategi Pengembangan Ekowisata Mangrove di Kecamatan Sungai Apit Kabupaten Siak. Jurnal Online Mahasiswa Fakultas Ilmu Sosial dan Ilmu Politik Universitas Riau, 4 (2) : 1-15.

Fitriana, D, Johan, Y, dan Renta, P, P. 2016. Analisis Kesesuaian EkowisataMangrove Desa Kahyapu Pulau Enggano. Jurnal Enggano. 1 (2) : 64-73.

Gunarto.2005. Konservasi Mangrove Sebagai Pendukung Sumber Hayati Perikanan Pantai. Jurnal Litbang Pertanian.

Hernandi, K., Sukojo, B. M., dan Parwati, E. 2013. Studi Tingkat Kerapatan Mangrove Menggunakan Indeks Vegetasi. Jurnal teknik pomits. 4 (4) : 1-6.

Imran, A dan Efendi, E. 2016. Inventarisasi Mangrove Di Pesisir Pantai Cemare Lombok Barat. Jurnal Pendidikan Mandala. 1 (1) ; 105-112.

Karimah. 2017. Peran Ekosistem Hutan Mangrove Sebagai Habitat Untuk Organisme Laut. Jurnal Biologi Tropis. 17 (2) : 51-58.

Malik, M. 2011. Evaluasi Komposisi dan Struktur Vegetasi Mangrove di Kawasan Pesisir Kecamatan Tugu Kota Semarang [Skripsi] Universitas Negeri Semarang.

Mariati W. 2016. Pengembangan Ekowisata Dikawasan Desa Anak Setatah Kabuapaten Kepulauan Meranti Provinsi Riau [Tesis]. Bogor. Institut Pertanian Bogor.

Masiyah, S dan Sunarni. 2015. Komposisi Jenis dan Kerapatan Mangrove Di Pesisir Arafura Kabupaten Merauke Provinsi Papua. Jurnal Ilmiah Agribisnis dan Perikanan. 8 (1) : 60-68.

Muhammad, F. Basuni, S. Munandar, A. Purnomo, H. 2012. Kajian Daya Dukung Ekowisata Hutan Mangrove Balanakan, Subang, Jawa Barat. Jurnal Bioma. 14 (2) : 64-71.

Mukhlisi. 2017. Potensi Pengembangan Ekowisata Mangrove Di Kampung Tanjung Batu, Kecamatan Pulau Derawan, Kabupaten Berau. Jurnal Manusia \& Lingkungan. 24 (1) : 23-30.

Noor Y R., Khazali. M dan Suryadiputra INN. 2006. Panduan Pengenalan Mangrove di Indonesia. Bogor: PHKA/WI-IP.

Notoatmodjo, S. 2010. Metodologi Penelitian Kesehatan. Rineka Cipta. Jakarta.

Nugraha, H.P., A. Indarjo, dan M. Helmi. 2013. Studi Kesesuaian dan Daya Dukung Kawasanuntuk Rekreasi Pantai di Pantai Panjang KotaBengkulu. Journal of Marine Research. 2 (2) : 130-139.

Parmadi, JC, E. H. . Dewiyanti, I. dan Karina, S. 2016. Indeks Nilai Penting Vegetasi Mangrove di Kawasan Kuala Idi Kabupaten Aceh Timur. Jurnal Ilmiah Mahasiswa Kelautan dan Perikanan Unsyiah. 1 (1) : 82-95.

Ramadhan S, Patana P dan Harahap Z A. 2014.Analisis Kesesuaian dan Daya Dukung Kawasan Wisata Pantai Cermin Kabupaten Serdang Bedagai

Romimohtarto. K dan Juwana. S. 2001. Biologi Laut, Ilmu Pengetahuan Tentang Biologi Laut. Djambatan. Jakarta.

Sadik M, Hamzah A M, Ukkas M. 2017. Kesesuaian Ekowisata Mangrove Ditinjau Dari AspekBiogeofisik Kawasan Pantai Gonda Di Desa Laliko Kecamatan Campalagian Kabupaten Polewali Mandar. Spermonde. 2 (3) : 25-33.

Savira N. Hartoko A. dan Adi W. 2018. Perubahan Luasan Mangrove Pesisir Timur Kabupaten Bangka Tengah Menggunakan Citra Satelit ASTER. Jurnal Sumberdaya Perairan. 12 (1) : 53-60.

Sawitri R., Bismark M, dan Endang K. 2013. Ekosistem Mangrove sebagai obyek wisata alam dikawasan konservasi mangrove dan bekantan dikota tarakan. Jurnal penelitian hutan dan konservasi alam. 10 (3) : 297-314.

Setiawan H. 2013. Status Ekologi Hutan Mangrove Pada Berbagai Tingkat Ketebalan. Jurnal Penelitian Kehutanan Wallacea. 2 (2) : 104-120.

Setyawan, E, Muhammad, F dan Yulianto, B. 2014. Kesesuaian dan Daya Dukung Kawasan Untuk Ekowisata Mangrove Di Desa Pasarbanggi Kabupaten Rembangjawa Tengah. [skripsi]. Universitas Diponegoro.

Sugiyono. 2011. Metode Penelitian Kuantitatif, Kualitatif Dan R\&D. Afabeta. Bandung.

Surinati. 2007. Pasang Surut dan Energinya. Oseana. 32 (1) : 15-22.

Tuwo, A., 2011. Pengelolaan Ekowisata Pesisir dan Laut : Pendekatan Ekologi, Sosial-Ekonomi, Kelembagaan dan Sarana Wilayah : BrilianInternasional, Surabaya

UU RI No. 10 Tahun 2009 Tentang Kepariwisataan.

Wahyuni, S. Sulardiono, B. Hendrarto B. 2015. Strategi Pengembangan Ekowisata Mangrove Wonorejo, Kecamatan Rungkut Surabaya. Diponegoro.Journal Of Maquares. 4 (4) : 66-70.

Wardhani, MK. 2011. Kawasan Konservasi Mangrove: Suatu Potensi Ekowisata. Jurnal Kelautan. 4 (1) : $60-76$

Wati, MW dan Idajati, H. 2017. Identifikasi Karakteristik Pengelolaan Ekowisata Mangrove Wonorejo Berdasarkan Preferensi Stakeholder. JURNAL TEKNIK ITS. 6 (2) : C575-C578 
Wibisono MS. 2004. Pengantar Ilmu Kelautan. Jakarta : PT Grasindo.

Wibowo, 2015. Studi Kesesuaian Ekowisata Mangrove di Kecamatan Kampung Melayu Kota Bengkulu. Program Studi Ilmu Kelautan. Skripsi. Fakultas Pertanian. Universitas Bengkulu.

Yulianda, F. 2007. Ekowisata Bahari Sebagai Alternatif Pemanfaatan Sumberdaya Pesisir Berbasis Konservasi. Makalah Seminar Sains 21 Februari 2007. Departemen Manajemen Sumberdaya Perairan Fakultas Perikanan dan Kelautan. Institut Pertanian Bogor. Bogor. 